\title{
El "clave bien temperado" de Felisberto Hernández
}

\section{The "Well-Tempered Clavier" of Felisberto Hernández}

\author{
Elvira Aballí Morell \\ Vanderbilt University, Estados Unidos \\ elvira.aballi.morell@vanderbilt.edu
}

Resumen: El interés de los críticos e investigadores en la obra de Felisberto Hernández se ha incrementado desde su inserción en el campo cultural a través de las valoraciones de Julio Cortázar y de Italo Calvino. No obstante, la intersección entre la literatura y la música en la obra de Hernández no ha sido suficientemente atendida a pesar de la evidente amalgama entre ambos campos. Esta investigación intenta saldar ese adeudo mediante un análisis interdisciplinario que permita decodificar la presencia de la música en la obra de Hernández y su contribución a la narrativa de este autor. El conocimiento musical y la experiencia como intérprete de Hernández se traducen en su obra a través del empleo de un imaginario musical y del uso del personaje del pianista; en la obra hernandiana se puede detectar la presencia de estructuras propias del discurso musical entre las cuales sobresale la organización del relato a partir de macroformas y de microformas, del uso de la dinámica -tanto por planos sonoros como por reguladores-, de la agógica y de los silencios, como ejes del discurso narrativo.

Palabras clave: música, literatura latinoamericana, Uruguay, silencio, barroco.

Abstract: Critical interest in the work of Felisberto Hernández has increased since Julio Cortázar and Italo Calvino brought recognition to his writing and incorporated him into the cultural field. However, the intersection between literature and music in Hernández's stories has not been sufficiently addressed, despite the evident amalgam between both 
fields. This article attempts to fill this critical lacuna through an interdisciplinary analysis that decodes the presence of music in the work of Hernández and examines its contribution to the narrative of this author. Hernández's musical knowledge and experience as an interpreter are translated into his work through the use of both a musical imaginary and the character of the pianist. The presence of musical discourse can be detected in his work, specifically through macroforms and microforms, dynamics, and agogic.

Keywords: Music, Latin-American literature, Uruguay, Silence, Baroque.

Recibido: 30 de junio de 2018 Aceptado: 15 de septiembre de 2018 http://dx.doi.org/10.15174/rv.v0i24.389

Zn el "extraño caso" de Felisberto Hernández (1902-1964) su Cexperiencia como intérprete se infiltró en su escritura, lo cual provocó que su narrativa se diferenciara radicalmente de la del resto de sus contemporáneos. En 1932, Petit Muñoz sentenciaba en su libro El camino: "a pesar suyo, y porque su vena existe [...] seguirá siendo músico, además de proseguir con su singular literatura” (1932: 475). Felisberto no tuvo reconocimiento internacional como pianista, a pesar de su brillantez y su precocidad. Desde muy joven, manifestó su deseo de escribir, canalizado inicialmente en las tertulias del filósofo Carlos Vaz Ferreira. ${ }^{1}$

Esther de Cáceres -admiradora e integrante del círculo de amigos y protectores nucleados en torno a Vaz Ferreira- reflexiona sobre cómo desde los inicios de su amistad, Felisberto "respondía con

${ }^{1}$ En estos encuentros, Felisberto Hernández no sólo amenizaba al piano, sino que también leía escritos incipientes que los contertulios del filósofo estimulaban. No obstante, críticos como José Pedro Díaz reconocen como su primer guía literario a José Pedro Bellán. Bellán fue, además, quien introdujo a Hernández en las tertulias de Vaz Ferreira. 
aire terco y desolado a los elogios que lo señalaban como un pianista excelente: ‘Yo quiero ser escritor!” (Apud. Díaz, 1999: 39). A pesar de su temprana decisión de convertirse en escritor y el apoyo de los intelectuales uruguayos más prominentes de su tiempo, Felisberto fue el menos famoso de los autores de su generación. ${ }^{2}$ Las primeras tiradas de sus libros no superaron los 200 ejemplares y no fue hasta 1947, con la publicación de Nadie encendia las lámparas por la editorial Sudamericana, que su obra alcanzó una mayor difusión. Debemos su (re)conocimiento y su posicionamiento en el "campo cultural" -en términos bourdieurianos-, principalmente, al escritor Julio Cortázar, a pesar de que otros notorios intelectuales como Italo Calvino, Juan Carlos Onetti, Jules Supervielle y Raúl Blengio, le rindieran elogiosos tributos. ${ }^{3}$ En el acercamiento de Cortázar a su obra sobresale la "Carta en mano propia" -que nunca leyera Felisberto- en la cual Cortázar prefigura el impacto que hubiera tenido en su vida el haberle conocido, puesto que ambos coincidieron en Chivilcoy. ${ }^{4}$ Dicha carta ha devenido en un intertexto indispensable en la valoración crítica del maestro:

${ }^{2}$ Según cuenta Gabriel Saad, es posible que se le considerara una persona de importancia política. Felisberto Hernández estuvo casado con una espía rusa, María Luisa Las Heras (África Las Heras Gavilán), de la cual Saad afirma que tuvo como "misión" de la KGB casarse con el escritor y vigilarlo de cerca, debido a su conducta anticomunista. Se puede consultar al respecto de José Pedro Díaz el acápite "Su viaje a Francia y el retorno (1946-1949)" en Felisberto Hernández: Su vida y obra. Para mayor profundización en la vida de Las Heras, véase la novela biográfica de Raúl Vallarino, Mi nombre es Patria.

${ }^{3}$ Puede consultarse en este sentido la Valoración Crítica editada por Walter Rela y Elisa Rey (1982).

${ }^{4}$ Julio Cortázar había descubierto, mediante la lectura del epistolario de Hernández, compilado por Norah Giraldi -Felisberto Hernández: Del creador al hombre de 1975-, que ambos habían coincidido en Chivilcoy por el año 1939. 
Es cierto que a mí no me hizo falta encontrarte en Chivilcoy para que años más tarde me deslumbraras en Buenos Aires con "El acomodador" y "Menos Julia" y tantos otros cuentos; es cierto que si hubieras sido un millonario guatemalteco o un coronel birmano tus relatos me hubieran parecido igualmente admirables. Pero me pregunto si muchos de los que en aquel entonces (y en éste, todavía) te ignoraron o te perdonaron la vida, no eran gentes incapaces de comprender por qué escribías lo que escribías y sobre todo por qué lo escribías así, con el sordo y persistente pedal de la primera persona, de la rememoración obstinada de tantas lúgubres andanzas por pueblos y caminos, de tantos hoteles fríos y descascarados, de salas con públicos ausentes, de billares y clubs sociales y deudas permanentes. Ya sé que para admirarte basta leer tus textos, pero si además se los ha vivido paralelamente, si además se ha conocido la vida de provincia, la miseria del fin de mes, el olor de las pensiones, el nivel de los diálogos, la tristeza de las vueltas a la plaza al atardecer, entonces se te conoce y se te admira de otra manera, se te vive y convive... (1985: XII).

La "Carta en mano propia” constituye una declaración genealógica, en la cual Cortázar reconoce su ascendencia literaria hernandiana, manifiesta en el propio acto de "vivir[lo]". ${ }^{5}$ Cortázar no sólo parte de la frase del músico Anton von Webern -cultivador de la microforma musical- para iniciar su misiva, sino que alude al "sordo y persistente pedal de la primera persona” [mi énfasis], dando pistas

\footnotetext{
${ }^{5}$ Muchos críticos, entre ellos Juan Antonio Lira Aguirre, han señalado la relación entre Julio Cortázar y Hernández a nivel formal y estético, inclusive hasta ético. No es casual que el propio Cortázar exhumara, por así decirlo, la obra del pianista y escritor. Se pueden conectar muchos de los tratamientos del tópico de la música entre Cortázar y Hernández. A nivel funcional la manipulación narrativa del tiempo resulta medular para entender este diálogo.
} 
de la necesidad de acercarse al lenguaje literario de Felisberto Hernández, desde el lenguaje musical. ${ }^{6}$

En este acercamiento propongo una lectura de los relatos de $\mathrm{Fe}-$ lisberto que permita decodificar la presencia de relaciones funcionales y estructurales en cuanto al uso del lenguaje musical, como parte de una estética de lo barroco en sus narraciones. Con esta finalidad analizo aquellos elementos que evidencian la presencia de ese "sordo y persistente pedal" de una fuga bachiana en la narrativa hernandiana: entre los que sobresale la agógica -variaciones en el tiempo y la duración-, la dinámica -variaciones en la intensidad y en la articulación-, los usos del silencio y la estructuración narrativa en macro y microformas.

\section{II}

Felisberto se vincula desde muy joven a las tertulias del filósofo Vaz Ferreira. A este período se deben tres de las once piezas musicales que compuso y que han quedado para la posteridad (Mimosismos, Canción repreciosa y El niño dormido). Eugenio Petit Muñoz menciona que la única partitura publicada por el pianista fue retirada por él mismo, pues la consideraba de poca calidad, además de que sólo guardaba algunas en versiones manuscritas. Petit describe las piezas escritas por Felisberto de la siguiente manera: "[tienen una] armonización absurda, entre trágica y humorística, con su lenta y cargosa inestabilidad, que jamás reposa” (1932: 475-76). Las obras literarias hernandianas, comprendidas entre 1925 y 1931, cuyo ex-

\footnotetext{
${ }^{6}$ Algunos autores han asociado y, de alguna manera, subordinado los términos musicales al campo semántico de lo literario para acercarse a la creación hernandiana -de estos intentos sobresalen las valoraciones de Italo Calvino, las de José Pedro Díaz, Norah Giraldi y Jorge Panesi-, pero ninguno ha decodificado los cuentos y las novelas cortas de Felisberto Hernández desde una apropiación del lenguaje musical como intentamos hacer en este artículo.
} 
ponente más emblemático es El libro sin tapas (1928), gozan de un fuerte aliento vanguardista, que se emparenta, según la descripción de Petit Muñoz, con la estética de sus primeras piezas musicales:

Este libro es sin tapas

porque es abierto y libre:

se puede escribir antes

y después de él. (Hernández, 1929: 3)

Los primeros libros de Felisberto Hernández -Fulano de tal (1925), Libro sin tapas, La cara de Ana (1930) y La envenenada (1931) - son publicados sin tapas, por la precariedad económica bajo la cual se les da a luz. Felisberto concibe el libro como un artefacto que puede ser modificado, no sólo en el hecho de completar los vacíos de significación propios del acto de la lectura, sino desde la idea del libro como un dispositivo que puede mutar a través de la intervención de la escritura. El lector hernandiano es concebido con el mismo poder transformador del intérprete musical. Felisberto demanda un receptor activísimo y reconoce la constante reactualización a la que expone su libro. Desde las primeras palabras del Libro sin tapas, se accede a un libro-cuerpo en constante cambio. Igualmente, la obra de Felisberto está permeada de las discusiones teóricas de estos años sobre los “ismos" en el arte de las primeras tres décadas. ${ }^{7}$ Existe una conferencia - de contenido teórico-literario- dictada en 1925 por Vaz Ferreira, titulada "Sobre la sinceridad literaria”, que influye potentísimamente la escritura hernandiana, como igual ocurrió con las teorías de Vaz Ferreira sobre la música pura, basada en lo que el filósofo denominaba "los

${ }^{7}$ Algunos críticos como José Pedro Díaz han enfatizado una profunda raigambre futurista en Felisberto Hernández (85). 
temperamentos puramente musicales" y la "imaginación acústica" (Petit Muñoz, 1932: 371).

Hernández proyecta su condición de músico y de pensador en sus relatos. En su obra vemos la preocupación por temas inherentes a la filosofía de la modernidad como son la soledad, la introspección y la incomunicación, así como la incompatibilidad de diferentes estados del ser en interacción con su entorno. Para Felisberto la creación literaria o la composición musical -a veces la mezcla de ambas en la página-partitura- constituyen un acto primordialmente imaginativo que pertenece al reino de la fantasía:

El concepto de la imaginación en la estética de Hernández ofrece paralelismos con lo formulado por Edmund Husserl sobre este mismo término en su fenomenología [...] es decir, para alcanzar este modo de "reflexión" el hombre tiene que cercenar sus ataduras con las premisas empiricistas y racionalistas (Rosario-Andújar, 1999: XII).

El autor-pianista establece una relación heterodoxa con los objetos que le rodean. En la obra de Felisberto, las cosas aparecen desfamiliarizadas y desprovistas de la conexión ordinaria con su espacio, por lo que carecen de esa correspondencia racionalista que los construye como significantes determinados. No sólo estaremos en presencia de un balcón suicida o ante un piano-sarcófago, sino que seremos conducidos de la mano de un narrador que deja a un lado el "ser objetivo". El narrador de Felisberto se define como un "intérprete y difundidor del espectáculo", "productor de sonidos, de sentidos", en el que "la cohesión de la información que da lugar al cuento, aparentemente dislocado, llega a lograrse por los efectos de una conciencia [narrativa] que podríamos llamar musical" (Giraldi, 1997: 136). Se trata de "prescindir de todo prejuicio de tipo naturalístico y metafísico, y de referirse a la esencia de los modos 
de conocer [...] y [de] la disponibilidad, la apertura de la consciencia al objeto" y a una agudización de los sentidos "interpretativos" (1999: XII) -en toda la extensión de la palabra-.

Hernández no sólo anticipa a Husserl, sino que es uno de los más claros exponentes del intuicionismo vital de Henri Bergson, al privilegiar la intuición como forma de conocimiento. En "Menos Julia", por ejemplo, la realidad material se subordina y aparece contaminada, difusa y fragmentada. Son los dedos y las manos que palpan o los oídos que escuchan, los que crean sus propios horizontes, en el marco de una dialéctica que se remonta al socorrido tópico barroco del engaño y el desengaño. Por eso, la realidad circundante de los personajes de Hernández nos desconcierta, en medio de esa aparente sobreabundancia del ambiente, muchas veces irreal, onírico. Para Husserl cosas que no pertenecen al plano de la realidad, pueden, igualmente ser representadas. Para ejemplificar este fenómeno mental, Husserl se enfoca en el caso del centauro -figura mítica que constituye una "representación de lo representado" - una creación de la imaginación del hombre, "una “irrealidad", que puede mantener su trascendencia "vis-á-vis con la mente" (Rosario-Andújar, 1999: 14). Sin embargo, en los relatos de Felisberto no se parte de un ser mítico, sino de la transformación mítica de la realidad. El lector de Felisberto se torna un "perplejo", desdichadamente, sin "manual".

Rosario-Andújar denomina "intuición sensible" a esta capacidad de Felisberto de darse narrativamente en escorzos, "a través de infinitos cambios" y puntos de fuga (1999: 14). Felisberto articula su relato a base de un conjunto de sfumatos e impresiones violentas, presentados de lo general a lo particular, como ocurre en Las meninas velazqueñas. ${ }^{8}$ Se fragmentan y se obscurecen los

${ }^{8}$ Jeremy Robbins se refiere a esta técnica de las impresiones del pincel en el arte pictórico de Diego Velázquez como "brush-strokes" (borrones, golpes de 
centros -como la composición de un mosaico- por el código de los reflejos -caleidoscópicos- en el espejo y en el agua -de "La casa inundada”-. Al respecto apunta Washington Lockhart:

Su visión no será por consiguiente una elaboración de los sentidos, sino, al contrario, una supeditación de lo percibido a su capacidad de reconstruir, desde un yo cautamente desligado, una realidad exterior, en donde cada cosa, milagrosamente, adquirirá relieve poético y representación de las zonas secretas e indecibles, inalcanzables para una mera apreciación sensorial (1991: 6-7).

El joven que estrena Petrouchka, en Buenos Aires, en reducción para piano, no dista mucho en sus narraciones de la estética stravinskiana -de un neobarroquismo musical-. En los cuentos de Felisberto, se atisba esa nueva forma narrativa, ese continuun "musical" de las palabras y esa visión o metaforización subjetiva de la realidad propia del intérprete, que deviene, finalmente, un estilo caro al autor.

\section{De pianistas y pianistas. Piano e intérprete, ¿dos caras de una misma entidad?}

Para Italo Calvino el punto de partida de todos los relatos de Hernández es la figura del "pianista sin dinero, en donde el sentido de lo cómico transfigura la amargura de una vida tejida de derrota" (1985: 3). Norah Giraldi, por su parte, ve al pianista como una de las "figuras emblemáticas, de concentración de significaciones en la que se apoya el narrador de Hernández para crear este mundo de repeticiones y formas breves" (1997: 136). Ciertamente, en los cuentos de Hernández, existe una relación indisoluble entre

pincel). Véase al respecto The Challenges of Uncertainty (83). 
el sujeto escritor y el sujeto músico. Su obra narrativa parte del discurso musical -entendible al intérprete- como si el lector fuera capaz de reconocer los signos musicales en los cuentos. Esta dualidad discursiva de la palabra y de la nota, le permite a Felisberto asumir la realidad circundante a través de la mira del intérprete y con la inquietud filosófica propia de un artista de la palabra y de la música. No nos extrańa ver que el mundo de lo musical y de lo visual -herencia principal de su experiencia como pianista de cine mudo- se superpongan o se interrelacionen profundamente en sus narraciones.

Tanto el pianista del café (en "El cocodrilo" o de "Mi primer concierto") como el propio concertista (en "Mi primer concierto" o en "El balcón") nos llegan de la mano de un narrador en primera persona que, a través de sus más íntimas conmociones, revela sus percepciones de la realidad. ${ }^{9}$ Felisberto muestra las vicisitudes que acaecen al músico, al punto de convertir a sus personajes en mercenarios de la música. En estos cuentos accedemos a una de las principales problemáticas del intérprete: la obtención del apoyo financiero necesario para las realizaciones de los conciertos. Felisberto nos muestra cómo el mecenazgo -casi institucionalizadoha evolucionado en el siglo xx, y los músicos y, en particular, los concertistas, dependen del financiamiento como única forma para poder emprender las giras o producir sus conciertos. En voz del personaje principal de "El cocodrilo", un pianista frustrado que debe incursionar en la venta de medias, accedemos al siguiente testimonio:

Antes yo había cruzado por aquellas ciudades dando conciertos de piano; las horas de dicha habían sido escasas, pues vivía en

${ }^{9}$ Los cuentos de Felisberto privilegian el narrador en primera persona. De hecho, este elemento sólo varía en "Las hortensias". 
la angustia de reunir gentes que quisieran aprobar la realización de un concierto; tenía que coordinarlos, influirlos mutuamente y tratar de encontrar algún hombre que fuera activo (Hernández, 1985: 273).

El concertista no puede vivir de su arte y se ve obligado a tener un empleo alternativo: vender calcetines (en "El cocodrilo") o a amenizar en cafés (en "Mi primer concierto"). Estos "empleos alternativos" devienen una mácula social para el pianista. El personaje de "Mi primer concierto" discurre en torno a la censura a la que es sometido un concertista devenido pianista de cafés, a manos de los especialistas o del auditorio. El fenómeno es mucho más complejo. Nadie consigue mantener una profesión que no lo sostiene o bien puede ejercerla y vivir de la caridad. Aquellos que están ajenos a la circunstancia de este pianista no comprenden cómo un concertista tiene que ir a tocar a un café. Por otra parte, el pianista que vende calcetines ni siquiera puede optar por una manera honrada de expender su producto y tiene que llorar en los establecimientos para que, por piedad, los clientes le compren. Lo que más sobresale de este personaje es que conoce las potencialidades de mover los ánimos de su público comprador a través de una manipulación de la audiencia, que bien puede competir con la movilidad o el alcance del intérprete en el espacio de la sala de concierto por medio de la música. Este sujeto narra cuán fácil le resulta enjugar las lágrimas, en su estado de hipersensibilidad. El narrador alude indirectamente a la insatisfacción y a la impotencia de este personaje que, imbuido en las responsabilidades de lograr su sustento, tiene que hacer a un lado su carrera como pianista y padece los efectos de este desahucio profesional. Este sentimiento no dista mucho de aquel que pudo haber experimentado el propio Felisberto, como instrumentista, quien manifestó en diferentes ocasiones algo similar a su esposa Amalia, en el epistolario intercambiado con ella. Al 
respecto, Cortázar refiere en el Prólogo a La casa inundada y otros cuentos:

Basta iniciar la lectura de cualquiera de sus textos para que Felisberto esté allí, un hombre triste y pobre que vive de conciertos de piano en círculos de provincia, tal como él vivió siempre, tal como nos lo cuenta desde el primer párrafo (1975: s/p).

Tanto en "Mi primer concierto" como en "De gira con Yamandú", Felisberto alude a los innumerables obstáculos a los que debe enfrentarse el músico, sobre todo a partir de las dinámicas entabladas entre el intérprete y su público. En "De gira con Yamandú", por ejemplo, los artistas deben encarar a un auditorio infanto-juvenil que, por demás, no está preparado para enfrentarse al programa elegido y se burla en voz alta. Tanto el pianista del primer relato como el del segundo se enfrentan a la apatía de sus oyentes.

En la narrativa de Felisberto hay una correspondencia entre el personaje-intérprete y el piano, en la cual muchas de las características son transmitidas metonímicamente de uno al otro. En el cuento "En la casa de Irene", es muy interesante la relación que se establece entre la figura de la joven Irene y su piano, manifiesta en la existencia de una complicidad rayana en la intimidad. El piano deviene una extensión de su cuerpo y de su pensamiento: "Sin embargo, ella se entendía mejor que nadie con su piano, y parecía lo mismo del piano con ella. Los dos estaban unidos por continuidad" (s/p). En este fragmento, se refleja verbalmente el concepto de lo metonímico, siendo la metonimia un tipo de metáfora "por continuidad". Ocurre una transferencia de las emociones de Irene al piano y viceversa. El piano percibe, del mismo modo que Irene, el cortejo del joven enamorado. Este instrumento se ha feminizado y sede a los encantos y al tacto del pretendiente: 
Después me senté yo a tocar y me parecía que el piano tenía personalidad y se me prestaba muy amablemente. Todas las composiciones que yo tocaba me parecían nuevas: tenían un colorido, una emoción y hasta un ritmo distinto. En ese momento me daba cuenta que a todo eso contribuían, Irene, todas las cosas de su casa (ref).

El narrador/autor implícito -coincidentemente el pianista- recalca que todos los objetos de la casa ceden en la misma medida en que quizás lo hubiera hecho Irene. No obstante, esta súbita inspiración del intérprete: "Todas las composiciones que yo tocaba me parecían nuevas: tenían un colorido, una emoción y hasta un ritmo distinto" (ref), plantea también una intermediación del piano entre él y su arte, entre él e Irene. No sólo las teclas del piano ceden a la digitación del pianista, sino que el intérprete se deja llevar por el piano. En este caso, el narrador ha tratado al piano como una metonimia de Irene, en la que, de haberla tocado, ella "se hubiera prestado muy amablemente" (ref).

En el cuento "Mi primer concierto", el pianista tiene una especie de anagnórisis previa a la interpretación: "El día de mi primer concierto tuve sufrimientos extrańos y algún conocimiento imprevisto de mí mismo" (Hernández, 1985: 180). Este reconocimiento se da en una dimensión simbólica a través de la identificación de una unión entre sujeto intérprete y objeto interpretado. La comprensión no es sólo de sí, sino también de la indisolubilidad de la relación entre ambos. El pianista es deudo -en toda la extensión de la palabra- de su piano. Su propia vida depende del instrumento, al cual homologa con un sarcófago. ${ }^{10}$ Para el sujeto, la psicodepen-

${ }^{10}$ Lo mismo ocurre cuando uno de los espectadores traspasa la puerta del decorado: "miró el piano negro como si se tratara de un féretro. $\mathrm{Y}$ después todos me hablaban tan bajo como si yo fuera el deudo más allegado al muerto" (Hernández, 1985: 182). 
dencia es absoluta, y, como describíamos, devoradora, amenazante (al principio). En el texto "Mi primer concierto", el personaje repasa, una y otra vez, las notas que parece olvidar, en una lucha en contra de ese oblivion perpetuo, que padece cada intérprete en el acto de posesión de la melodía. La memoria auditiva juega un papel indispensable en la interpretación. Felisberto enfatiza, en este cuento, que tocar no es un proceso lineal y trata de mostrar la complejidad del pensamiento y de la cosmovisión del instrumentista:

me vino un calor extraño al estómago y tuve el presentimiento de un peligro inmediato. Reaccioné yendo a estudiar enseguida; pero como tenía varios días por delante, pronto empecé a calcular con el mismo error de siempre lo que podría hacer con el tiempo que me quedaba. Sólo en la mañana del concierto me di cuenta de todas las concesiones que me hacía cuando estudiaba y que ahora, no sólo no había llegado a lo que quería, sino que no lo alcanzaría ni con un año más de estudio. Pero donde más sufría era en la memoria (Hernández, 1985: 180).

El fracaso al memorizar la partitura se convierte potencialmente en el fiasco profesional del músico ya que el público espera una interpretación impecable. La impecabilidad de la ejecución se convierte en un foco delirante en la mente de este personaje y las notas falsas devienen una enorme amenaza a su prestigio profesional. Por otra parte, existe una relación de complicidad, donde, en apariencia, la marcha es dictada por el intérprete y no por el instrumento. En este relato la memoria presenta una constante amenaza. Sin embargo, la memoria no es la única antagonista del pianista, también encontramos el peligro del tiempo que, con su implacable poder, dicta los destinos de los hombres y la duración de las notas. Al final del relato no sabemos si el piano, la memoria o el tiempo 
llevarán al solista a su fracaso o si logrará dominar el instrumento y la melodía -lo fable-. El piano que representaba una amenaza deja de serlo y el pianista logra dominar-literalmente- al instrumento y a los peligros que ensombrecen su ejecución. Los límites de la violencia simbólica y antropófaga del piano se difuminan y se da paso al éxito del intérprete, el cual viene aparejado de una conquista de la audiencia y de la memoria y del tiempo -en un profundo diálogo con el tempus fugit barroco-. El antagonismo entre el piano y el pianista se ve también en el relato "El balcón", en el cual, para silenciar al intérprete el piano quiebra una de sus cuerdas. El piano es "consciente" de la situación y deviene otro personaje de la historia, no es simplemente un objeto. En él recae el ascenso o declive del intérprete -en una lucha encarnizada por el poder-.

En "Mi primer concierto" el espacio es el de una pequeña sala de concierto, mientras que en el cuento "En la casa de Irene" se trata de la pieza de una vivienda -la saleta o boudoir-. Ambas áreas constituyen para Carlos Bosh el espacio concertante de cámara, el cual interviene en las relaciones del intérprete con su audiencia e inclusive en la concepción que el intérprete tiene de sí mismo. El espacio de cámara barroco potencia una perspectiva individualísima, aunque no ocurra un "recogimiento [...] íntimamente meditativo, sino de influencias exteriores caldeadas en cámara privada" (Bosh, 1932: 186). Este elemento es esencial para entender no sólo las introspecciones del personaje del pianista hernandiano, sino su pugna con lo ampliamente social (el público). El pianista narrador de Felisberto se construye desde una profunda interioridad, desde un "adentro hacia afuera", en una especie de "arte claustral". ${ }^{11}$ Cuando Bosh describe a los "contrapuntistas" parece

${ }^{11}$ El personaje del pianista, casi siempre el narrador, nos brinda las más profundas disquisiciones sobre su técnica pianística -que puede variar desde la forma de saludar al público hasta el énfasis en la forma de la pieza a interpretar-. 
que está refiriéndose a los narradores-pianistas felisbertianos en los que "siempre parece latente este sentimiento de construcción de afiligranados idealismos" (1932: 190). Esta metáfora de la filigrana, como técnica artesanal, es fundamental para entender el artefacto hernandiano, no sólo desde la urdimbre filosófica de su escritura, sino también desde la implementación de diferentes niveles subjetivos en el relato.

\section{Continuun narrativo. Macroformas y microformas}

Al inicio del siglo xx, Anton von Weber -el compositor citado por Cortázar en la "Carta en mano propia"- sistematiza los procedimientos de la microforma, aunque la microforma tiene sus antecedentes más importantes en el siglo xx con piezas para piano como los Nocturnos, los Impromtu, los Momentum musicales y otras, de carácter programático, como los Lieder y las Baladas, de autores románticos como Frederick Chopin y Franz Schubert. Webern condensa en la microforma el elemento contrapuntístico y privilegia el valor del timbre o del color de los instrumentos. ${ }^{12}$ En relatos como "Elsa" y "El vestido blanco", encontramos cuentos anclados en una estética weberiana de lo microformal, mediante una concentración expresiva: una mayor sencillez sintáctica manifiesta por medio de poca subordinación oracional, así como de una estructura en párrafos breves.

Sin embargo, al adentrarnos en la obra de Felisberto Hernández detectamos determinados núcleos temáticos afiligranados. De ahí que se puedan leer sus escritos como partes o movimientos de un conjunto mayor (en un nivel macroformal). Norah Giraldi

${ }^{12}$ El Klangfarbenmelodie constituye uno de los principales métodos para diversificar o jugar con el timbre instrumental mediante la partición de la línea melódica en secciones permitiendo que la línea melódica pase por diferentes instrumentos. 
ha notado, en el análisis de los aforismos y las notas escritas entre 1925 y 1931, que estos textos contienen "una semilla que da variaciones sobre un mismo tema que se suceden [...] como pliegues o cortes" (Giraldi, 1997: 134). Es decir, los aforismos y las notas de Felisberto no sólo recrean un tema a nivel microformal -con gran economía expresiva- sino que, vistos en su conjunto, se pueden tejer conexiones o filigranas entre ellos. Giraldi propone una lectura macroformal -aunque no exactamente en estos términos- de los títulos, aforismos y notas sueltas de Felisberto,

como forma breve, doble productora de sentido, ya que sienta las bases de la problemática del texto, y es signo que plasma un movimiento ininterrumpido, de fuga de una escritura que se preocupa del instante [...] ese 'pensamiento fugaz' que se abandona por otro tema, por otro motivo, genera un movimiento metonímico que es la propia dialéctica de su lenguaje poético" (1997: 135; el énfasis es mío).

En textos como "La casa inundada" o "El acomodador", vemos esos núcleos narrativos distendidos, o "una variación" -como dice Giraldi- en el propio relato: un tema es recreado, una y otra vez, pasando por diferentes estadios, como si fuera un "Tema con variaciones". En "La casa inundada", el propio tópico del agua es uno de esos núcleos narrativos amplificados; en "El acomodador", el tema de la muerte deviene en otro tipo de núcleo (que va desde la expiración física, hasta la muerte del espíritu). Ambos temas, vistos desde una microforma, en el sentido global del relato, funcionan perfectamente sobre la base de una idea fija o un motivo que es recreado hasta la multiplicidad total. ${ }^{13}$

${ }^{13}$ En "El acomodador", lo microformal se concentra más bien a un nivel sintagmático por medio del uso de paralelismos sintácticos. 
Podemos rastrear en la obra de Felisberto la gran presencia del tema de la muerte, el cual se puede ver desde la microforma-como un relato independiente y sintético-, pero también podría constituir un macroconjunto, una forma más grande, una macroforma: varios movimientos, un tipo de novela fragmentada, donde varios relatos cobran unidad de sentido en la medida en que se complementan mutuamente. Si analizamos el tópico de la muerte como un macroconjunto, podemos conectar dos cuentos aparentemente distantes entre sí como son "El acomodador" y "El balcón". A pesar de que en el último la muerte no es humana, sino que se trata del suicidio de un balcón, descrito por medio de la focalización de una joven de la que, aparentemente, éste se ha enamorado. Un balcón "suicida" y "celoso" que se ha desplomado víctima de la impotencia. La impotencia es otro de los focos temáticos del Felisberto y constituye un tema redondeado a nivel macroformal en relatos como "El balcón" o en "El acomodador" o "La casa inundada".

Otro tema que pudiera formar un macroconjunto de sentido es la relación de lo inanimado con las personas mediante el contacto, presente en cuentos como "El balcón” y "Menos Julia”. ${ }^{14}$ Podemos agrupar tres de estos relatos en una macroforma, una especie de concierto en tres movimientos, "El acomodador" y "Menos Julia" (I y II) se entrelazan o relacionan con un tercero ("El balcón). Felisberto tiene obsesiones poéticas, que se manifiestan en el plano temático a dos niveles: intra-relato o extra-relato, constituyendo macro o microformas narrativas. ${ }^{15}$

${ }^{14}$ En este relato, así como en "Historia de un cigarrillo", se ve al objeto como un ente, que puede ser dotado de propósito.

${ }^{15}$ Norah Giraldi ha visto en "El acomodador" la estructura de un concierto en tres movimientos con una coda final. Consúltese al respecto: "Felisberto Hernández y la música”. 


\section{La dinámica y la agógica en Felisberto Hernández}

El contraste es un elemento caro a Felisberto, tanto por el uso de la agógica (ritardandos y acelerandos en el relato, indistintamente) como por el uso de la dinámica (a nivel de un empleo consciente de los crescendos y decrescendos y de la manipulación por planos sonoros), que pueden decodificarse a partir de marcas explícitas en el texto: gritos, interjecciones, vacíos prolongados de diálogos entre los personajes y por las propias alusiones a los cambios temperamento y al movimiento del cuerpo.

Encontramos relatos cuyo tempo resulta extensamente dilatado (una especie de Largo) como ocurre en el caso de "La casa inundada" y en "Mi primer concierto". Podemos encontrar otros brevísimos, de rápido movimiento (Vivace), estructurados en pequeños bloques monolíticos (a manera de movimientos musicales breves: microformas).

En textos como "Mi primer concierto" aparece de manera más explícita -en terminología musical- el sentido de la agógica en Felisberto. El segmento que expongo a continuación es una muestra clara de rejuego, antes aludido en el terreno de interpretación pianística, propiamente:

De pronto me incliné sobre el piano, lo apagué bruscamente y empecé a picotear un "pianísimo" en los agudos. Después de este efecto se me ocurrió improvisar otros. Metía las manos en la masa sonora y la moldeaba como si trabajara con una materia plástica y caliente; a veces me detenía modificando el tiempo de rigor y ensayaba dar otra forma a la masa; pero cuando veía que estaba a punto de enfriarse, apresuraba el movimiento y la volvía a encontrar caliente (Hernández, 1985: 183-184). 
El fragmento anterior constituye, teóricamente, la expresión del principio narrativo que busca Felisberto. En sus cuentos se da esa intención de modelar la "masa amorfa" -que bien puede ser acordes y notas o palabras y párrafos-. En "Mi primer concierto" se ralentiza el tempo durante el momento previo a la actuación. En la primera sección del cuento, el concertista recrea una especie de coreografía por pasos, minuciosamente diseñada. Luego, en la segunda parte -el concierto- esto cambia mediante un acelerando radical del tempo narrativo. En "La casa inundada", por otra parte, la estancia del invitado en la morada de la Sra. Margarita se nos alarga infinitamente y presenciamos un ritenuto constante en cada una de las escenas. En "Menos Julia" ocurre algo similar, hay un desacelerando o ritardando: "A medida que iba oscureciendo mi amigo hablaba menos y hacía movimientos más lentos" (Hernández, 1985: 161). En este mismo relato el visitante camina de un lado al otro de su habitación y el anfitrión le dice: "—-Tus pasos no me dejan tranquilo; se oyen demasiado allá bajo" (1985: 164). Ante el requerimiento del anfitrión, el personaje se descalza y comienza a desplazarse con medias y el dueño de la casa asevera que aún lo escucha. Aquí ha ocurrido el empleo de una exacta dinámica por planos -típica del barroco musical- donde un primer plano ha sido exactamente estable y mezzo forte $(m f)$ frente a un segundo que ha sido igualmente estable, pero mezzo piano $(m p)$. En "El balcón”, en virtud de un concepto similar, se juega con la dinámica y con la agógica:

apenas empezaba el verano la casa se ponía triste, iba perdiendo sus mejores familias y quedaba habitada nada más que por los sirvientes. Si yo me hubiera escondido detrás de ella y soltado un grito, éste enseguida se hubiese apagado en el musgo (Hernández, 1985: 134). 
$\mathrm{Al}$ inicio del pasaje anterior, el narrador describe todo en un tempo estable, sobre lo Larghetto (reforzado, también, por el empleo del adjetivo "triste") y que se desarrolla en lo mezzo piano. $\mathrm{Al}$ incluir la frase "soltado un grito", dentro de toda la quietud descrita previamente, nos hace acelerar el tempo narrativo y llegar a un forte $(f)$ o fortissimo (ff), abruptamente, casi como si estuviera haciendo cine. Luego, con la frase "se hubiese apagado en el musgo", nos hace retomar el tempo precedente y el lector experimenta la sensación de un pianissimo $(p p)$. Persiste en Felisberto una finalidad expresiva muy similar a la que puede lograrse en una interpretación musical. Pudiéramos citar no sólo aquellos relatos cuyo centro es el pianista, sino otros cualesquiera, ya que, en el acto de crear el relato, Felisberto está haciendo música. ${ }^{16}$

\section{El silencio en Felisberto Hernández}

El silencio desempeña un papel fundamental en el mundo sonoro de los relatos de Felisberto Hernández. Los susurros, los decrescendos y los mutismos coadyuvan al despliegue expresivo de sus cuentos. ${ }^{17}$ En sus historias se pueden identificar varios tipos de silencio: uno que podríamos llamar "complementario", parecido a los silencios reflejados en la partitura -silencios de corta duración, que no interrumpen radicalmente la curva melódica- como ocurre en este

${ }^{16}$ Otro recurso del que se vale es la letanía, por ejemplo, en el uso de la letanía del agua en "La casa inundada", con la cual se pretende distender el plano dramático y a su vez fortalecer el manejo de un aire prolongado, cíclico, por cuanto el da capo manifiesto, en dicho recurso, afecta a nivel estructural y de sentido al cuento. De igual manera ocurre en "El balcón" donde la letanía es el silencio, quien será retomado con asiduidad para lograr el efecto antes mencionado.

${ }^{17}$ El silencio aparece dotado de una especie de fisicidad: "Al silencio le gustaba escuchar la música" o "el silencio parecía un animal pesado que hubiera levantado una pata". 
fragmento: "cuando el silencio ya era de confianza, intervenía en la música: pasaba entre los sonidos como un gato con su gran cola negra y los dejaba llenos de intenciones” (Hernández, 1985: 133); un segundo tipo es aquel que se manifiesta gradualmente en este pasaje por medio de un diminuendo: "El público hizo un silencio como el vacío que se siente antes del accidente que se ve venir" y en "hablábamos en voz cada vez más baja a medida que la luz se iba” (Hernández, 1985: 133-134), y un tercero en el que el silencio puede reflejarse como el vacío, aunque, este tipo en particular no implica necesariamente la inactividad o la insonorización, sino que puede ser un equivalente o una representación simbólica de la soledad:

Llegaba como un director de orquesta después que los músicos estaban prontos. Pero lo único que él dirigía era el silencio... El director hacía un saludo al sentarse, todos dirigían la cabeza hacia los platos y pulsaban sus instrumentos. Entonces cada profesor de silencio tocaba para sí (Hernández, 1985: 146).

Este último tipo de silencio, como bien reconoce el narrador, es un silencio "enfermizo" y contagioso, pues en la medida en que el protagonista asiste con mayor frecuencia a este comedor-donde entra en contacto con el dueño, "director del silencio"- se ha ido "enfermando de silencio" (147). Este silencio lo ha conducido a la autoexclusión. En este relato como en "La casa inundada", "el silencio, [manifiesto en] el no hablar [...] permite salir de esa situación es la presencia de un tercer elemento (simbólico): un vacío, una ausencia, una promesa de palabra (o relato) que el texto instaura mediante el corte" (Panesi: 1982: 134).

El silencio es una herramienta expresiva de la cual Felisberto se vale para manipular el universo sonoro de sus cuentos. La repre- 
sentación discursiva de las cesuras, los decrescendos, las carrasperas ${ }^{18}$ y los susurros sirven para darle cuerpo a esa "masa” que es el lenguaje. Felisberto maneja el texto como si fuera una gran partitura, en la que cada solista de la orquesta espera su turno. A veces, el silencio deviene la única herramienta efectiva para regular la polifonía de voces que se genera en las historias que recrean espacios más sociales, como es el caso del teatro o del salón de tertulias. Cada "profesor del silencio", representa perfectamente su papel en el gran coro del relato. En la narrativa hernandiana prevalece el silencio -aun cuando la palabra está presente-como la más pura manifestación de ese "sordo y persistente pedal" (mi énfasis) al que aludía Cortázar.

\section{Conclusiones}

A partir de la década de 1940 de la pasada centuria, se da un lento proceso de revalorización de Felisberto Hernández, que se concreta, satisfactoriamente, en 1960 con la aproximación crítica de Julio Cortázar. A pesar de que Hernández vendió su piano para dedicarse por completo a la escritura, volcó sobre el papel su irremediable vínculo con la música y lacró su creación literaria con el sello del intérprete. Como sentencia Petit Muñoz, Felisberto "seguirá siendo músico, además de proseguir con su singular literatura” (1932: 475).

El texto hernandiano fue concebido como un objeto sonoro, diseñado para ser leído/interpretado y transformado por el receptor. Hernández reniega de la formulación estática de la literatura $y$, por esta razón, es posible que nos cause la impresión de leer una

${ }^{18}$ Acerca de las carrasperas como sustituto de lo oral -en la manifestación de una "Margarita preverbal"- y la escritura como corte simbólico, puede consultarse "Felisberto Hernández, un artista del hambre (Análisis de La casa inunda$d a)$ " de Jorge Panesi. 
obra inacabada o de que sus cuentos carecen de un cierre a la manera "clásica", no obstante, su corpus narrativo puede entenderse/ leerse desde diversos elementos formales y expresivos que dicho autor sustrae y adapta del campo musical.

Este artículo privilegia la imagen del escritor-músico que fue. En su narrativa encontramos no sólo un imaginario del pianista, sino también varios recursos propios del lenguaje musical, los cuales subordina a una estética barroca para crear poderosos relatos a nivel semiótico. Felisberto supo enriquecer su creación mediante el uso consciente de la savia musical que poseía. Como músico, es dueño de una sensibilidad "otra”, que cristaliza en su obra.

\section{Bibliografía}

Antúnez, Rocío, 1985, Felisberto Hernández: El discurso inundado, Instituto Nacional de Bellas Artes y Katún, México, D. F.

Bosh, Carlos, 1932, En las cataratas de lo barroco, Espasa-Calpe, Bilbao.

Calvino, Italo, 1985, "Las zarabandas mentales de Felisberto Hernández", en Felisberto Hernández. Novelas y cuentos, José Pedro Díaz (ed.), Biblioteca Ayacucho, Caracas, pp. 3-5.

Cortázar, Julio, 1985, "Carta en mano propia”, en Novelas y cuentos, Ayacucho, Caracas, pp. IX-XIV.

, 1975, "Prólogo", en De "La casa inundada" y otros cuentos. Disponible en https://www.lainsignia.org/2003/marzo/ cul_009.html (Consultado en 01/XI/2017).

Díaz, José Pedro, 1999, Felisberto Hernández: Su vida y obra, Arca, Montevideo.

, 1991, Felisberto Hernández. El espectáculo imaginario, 1, Arca, Montevideo. 
Gamerro, Carlos, 2010, Ficciones barrocas: una lectura de Borges, Bioy Casares, Silvina Ocampo, Cortázar, Onetti y Felisberto Hernández, Eterna Cadencia Editora, Buenos Aires.

Giraldi Dei Cas, Norah, 1975, Felisberto Hernández, del creador al hombre, Ediciones de la Banda Oriental, Montevideo.

, 1997, "Las formas breves de Felisberto Hernández y de Juan Carlos Onetti", América: Cahiers du CRICCAL , vol. 1, núm. 18, pp. 133-43.

, 1982, "Felisberto Hernández y la música", Escritura, vol. 7, núm. 13-14, pp. 313-26.

Hernández, Felisberto, 1985, Novelas y cuentos, Ayacucho, Caracas.

, 1929, El libro sin tapas, Dominio Público.

, "La casa de Irene", disponible en: https://albalearning.com/ audiolibros/fhernandez/casa.html (Consultado: 01/XI/2017).

Lespada, Gustavo, 2014, Carencia y literatura. El procedimiento narrativo de Felisberto Hernández, Corregidor, Buenos Aires.

Lockhart, Washington, 1991, Felisberto Hernández: Una biografía literaria, Arca, Montevideo.

López-Terra, Federico, 2013, "El vacío fundante en la estética de Felisberto Hernández", Bulletin of Hispanic Studies, vol. 90, núm. 1, pp. 65-77.

Morillas Ventura, Enriqueta, 1983, La narrativa de Felisberto Hernández, Tesis doctoral, Universidad Complutense, Madrid.

Núñez, María Gracia y Tani, Rubén, 2005, "El artista, la crítica impresionista y la investigación sobre la producción artística", Espéculo, núm. 30. Disponible en: http://www.ucm.es/info/especulo/numero30/felihern.html.

Panesi, Jorge, 1982, "Felisberto Hernández, un artista del hambre”, Escritura, vol. 7, núm. 13-14, pp. 131-59. 
Perera San Martín, Nicasio, 1977, "Sobre algunos rasgos estilísticos de la narrativa de Felisberto Hernández", en Felisberto Hernández ante la crítica actual, Monte Ávila, Caracas, pp. 229-248.

Petit Muñoz, Eugenio, 1932, El camino: Etapas de una politica educacional vivida, La Cruz del Sur, Montevideo.

Renaud, Maryse, 1977, "El acomodador, texto fantástico", en $\mathrm{Fe}$ lisberto Hernández ante la critica actual, Monte Ávila, Caracas, pp. 257-278.

Robbins, Jeremy, 1998, The Challenges of Uncertainty: An Introduction to Seventeenth-Century Spanish Literature, Duckworth, Londres.

Rosario-Andújar, Julio A., 1999, Felisberto Hernández y el pensamiento filosófico. Peter Lang, Nueva York.

1982, La obra cuentística de Felisberto Hernández: "Escribir sobre lo que no se sabe", ProQuest Dissertations Publishing.

Saad, Gabriel, "Homenaje a Felisberto Hernández con motivo del cincuenta aniversario de su muerte organizado por Casa América”. Disponible en: https://www.youtube.com/ watch?v=Xs61ZO42Y8Y (Consultado 1/XI/2017).

, 1977, “Tiempo y espacio en algunas narraciones de Felisberto Hernández", en Felisberto Hernández ante la crítica actual, Monte Ávila, Caracas, pp. 279-290.

Sicard, Alain (comp.), 1977, Felisberto Hernández ante la critica actual, Monte Ávila, Caracas.

Walter, Rela y Elisa Rey, editores, 1982, Felisberto Hernández, valoración crítica, Editorial Ciencias, Montevideo. 